\title{
Benzyl isothiocyanate induces protective autophagy in human lung cancer cells through an endoplasmic reticulum stress-mediated mechanism
}

\author{
Qi-cheng ZHANG ${ }^{1}$, Zhen-hua PAN ${ }^{1}$, Bo-ning LIU ${ }^{1}$, Zhao-wei MENG ${ }^{2}$, Xiang WU ${ }^{3}$, Qing-hua ZHOU ${ }^{1}, K$ XU $U^{1, *}$ \\ ${ }^{1}$ Tianjin Key Laboratory of Lung Cancer Metastasis and Tumor Microenvironment, Tianjin Lung Cancer Institute, Tianjin Medical \\ University General Hospital, Tianjin 300052, China; ${ }^{2}$ Department of Nuclear Medicine, Tianjin Medical University General Hospital, \\ Tianjin 300052, China; ${ }^{3}$ Core Facility Center, Tianjin Medical University General Hospital, Tianjin 300052, China
}

\begin{abstract}
Isothiocyanates, such as allyl isothiocyanate (AITC), benzyl isothiocyanate (BITC), phenethyl isothiocyanate (PEITC) and sulforaphane (SFN), are natural compounds abundant in cruciferous vegetables, which have substantial chemopreventive activities against various human malignancies. However, the mechanisms underlying the inhibition of tumor cell growth by isothiocyanates are not fully understood. Since autophagy has dual functions in cancer, in the present study we investigated the effects of BITC on autophagy induction in human lung cancer cells in vitro and in vivo. BITC (1-100 $\mu \mathrm{mol} / \mathrm{L})$ dose-dependently inhibited the growth of 3 different human lung cancer cell lines A549 (adenocarcinoma), H661 (large cell carcinoma) and SK-MES-1 (squamous cell carcinoma) with IC ${ }_{50}$ values of $30.7 \pm 0.14,15.9 \pm 0.22$ and $23.4 \pm 0.11 \mu \mathrm{mol} / \mathrm{L}$, respectively. BITC $(10-40 \mu \mathrm{mol} / \mathrm{L})$ induced autophagy in the lung cancer cells, evidenced by the formation of acidic vesicular organelles (AVOs), the accumulation of LC3-II, the punctate pattern of LC3, and the expression of Atg5. Pretreatment with the autophagy inhibitor 3-MA (5 mmol/L) significantly enhanced the BITC-caused growth inhibition in the lung cancer cells. Furthermore, BITC (20-40 $\mu \mathrm{mol} / \mathrm{L})$ activated ER stress, as shown by the increased cytosolic Ca ${ }^{2+}$ level and the phosphorylation of the ER stress marker proteins PERK and elF2 $\alpha$ in the lung cancer cells. Pretreatment with the ER stress inhibitor 4-PBA ( $5 \mathrm{mmol} / \mathrm{L}$ ) attenuated the autophagy induction and potentiated the BITC-induced cell growth inhibition. In nude mice bearing A549 xenografts, administration of BITC (100 $\mathrm{mg} \cdot \mathrm{kg}^{-1} \cdot \mathrm{d}^{-1}$, ip) for 8 weeks markedly suppressed the lung tumor growth, and significantly enhanced both autophagy and ER stress in the tumor tissues. Our results demonstrate that BITC inhibits human lung cancer cell growth in vitro and in vivo. In addition, BITC induces autophagy in the lung cancer cells, which protects the cancer cells against the inhibitory action of BITC; the autophagy induction is mediated by the ER stress response.
\end{abstract}

Keywords: benzyl isothiocyanate; human lung cancer; autophagy; ER stress; LC3; PERK; 3-MA; 4-PBA

Acta Pharmacologica Sinica (2017) 38: 539-550; doi: 10.1038/aps.2016.146; published online 23 Jan 2017

\section{Introduction}

Lung cancer is the most common cause of death in men and second only to breast cancer in women. There are 1.82 million new cases diagnosed and 1.6 million deaths annually ${ }^{[1]}$. Nonsmall-cell lung cancer (NSCLC) accounts for approximately $85 \%$ of all cases of lung cancer. NSCLC can be subdivided by histological type into adenocarcinoma, squamous cell carcinoma, large-cell carcinoma and others. Surgery, chemotherapy and radiation therapy are the major strategies for lung cancer treatment; however, the 5-year relative survival rate is

\footnotetext{
*To whom correspondence should be addressed.

E-mail ke_xu@hotmail.com

Received 2016-09-27 Accepted 2016-11-15
}

approximately $15 \%^{[2]}$. Therefore, the development of novel anti-cancer drugs is urgently needed.

Autophagy is a process by which cells capture intracellular proteins, lipids and organelles and deliver them to autophagosomes. These autophagosomes fuse with lysosomes, and the sequestered contents are degraded. Autophagy serves as a cell survival mechanism, removing improperly folded proteins and acting as an alternative energy source ${ }^{[3]}$. Autophagy is involved in many pathophysiological processes, such as cancer, metabolic and neurodegenerative disorders, and cardiovascular and pulmonary diseases ${ }^{[4]}$. In cancer, the role of autophagy is complex and depends on tumor type, stage and genetic context. Autophagy has dual functions in cancer. It can act as a tumor suppressor by preventing the accumulation 
of damaged proteins and organelles. Alternatively, it can promote the growth of established tumors through intracellular recycling, which provides metabolic substrates ${ }^{[5,6]}$.

Isothiocyanates are natural compounds that are abundant in cruciferous vegetables such as broccoli, watercress and Brussels sprouts. Some isothiocyanates, such as allyl isothiocyanate (AITC), benzyl isothiocyanate (BITC), phenethyl isothiocyanate (PEITC) and sulforaphane (SFN), have been shown to have substantial chemopreventive activity against various human malignancies ${ }^{[7]}$. The mechanism of the isothiocyanate chemopreventive activity is thought to be associated with the inhibition of the metabolic activation of carcinogens by phase I enzymes (cytochrome P450 isozymes), and the increased excretion of carcinogens by inducing increased activities of phase II enzymes (quinone reductase and GSH S-transferases) ${ }^{[8,9]}$. Numerous studies have also demonstrated the anticancer effects of isothiocyanates in various cancer types, such as leukemia $^{[10]}$, breast cancer ${ }^{[11]}$, prostate cancer ${ }^{[12]}$ and lung cancer ${ }^{[13]}$. Isothiocyanates suppress tumor cell growth by causing oxidative stress, inducing apoptosis, causing cell cycle arrest, and inhibiting angiogenesis ${ }^{[9]}$. However, the mechanism underlying the growth inhibitory effect of isothiocyanates against cancer is not fully understood.

Our previous studies showed that isothiocyanates suppress the metastatic potential of lung cancer cells ${ }^{[14]}$ and induce apoptosis of lung cancer cells ${ }^{[13,15]}$. In the present study, we investigated the effect of BITC on the induction of autophagy in lung cancer cells and the influence of autophagy on the inhibitory effect of BITC.

\section{Materials and methods Materials}

BITC, 3-methyl adenine (3-MA), acridine orange (AO), 4-phenylbutyric acid (4-PBA) and chloroquine (CQ) were purchased from Sigma-Aldrich Inc (St Louis, MO, USA). Cell culture medium and fetal bovine serum (FBS) were purchased from Life Technologies (Carlsbad, CA, USA). Rabbit antibodies against microtubule-associated protein 1 light chain 3 (LC3), ATG5, PERK, eIF2 $\alpha$ and phospho-eIF2 $\alpha$ were purchased from Cell Signaling (Beverly, MA, USA); the rabbit antibody against phospho-PERK was purchased from Santa Cruz Biotechnology (Dallas, TX, USA); the mouse monoclonal antibody against $\beta$-actin was purchased from Sigma-Aldrich; the secondary antibodies coupled to HRP were purchased from ZSGB-BIO (Beijing, China). pSELECT-GFP-LC3 was purchased from InvivoGen (San Diego, CA, USA).

\section{Cell culture}

The human lung cancer cell lines A549, SK-MES-1 and H661 were purchased from the American Type Culture Collection (Manassas, VA, USA). The A549 and SK-MES-1 cells were grown and maintained in DMEM, while the H661 cells were grown and maintained in RPMI-1640 medium. All cell lines were maintained at $37^{\circ} \mathrm{C}$ and $5 \% \mathrm{CO}_{2}$. The culture medium was supplemented with $10 \%$ fetal bovine serum, $100 \mathrm{U} / \mathrm{mL}$ penicillin and $100 \mathrm{U} / \mathrm{mL}$ streptomycin.

\section{Cell viability assay}

A549, SK-MES-1 and H661 cells were seeded at an initial density of $2 \times 10^{5}$ cells/mL and incubated with $0-40 \mu \mathrm{mol} / \mathrm{L}$ BITC for $48 \mathrm{~h}$ at $37^{\circ} \mathrm{C}$. Dimethylsulphoxide (DMSO) was used as vehicle control. Stock solutions of BITC $(100 \mathrm{mmol} / \mathrm{L})$ were prepared in DMSO and diluted in the growth medium such that the final concentration of DMSO did not exceed $0.05 \%$ $(v / v)$, a concentration that did not induce toxicity in cells. The cell viability was determined by the Cell Counting Kit-8 (Dojindo, Kumamoto, Japan) following the manufacturer's instruction. The median inhibitory concentration $\mathrm{IC}_{50}$ values were calculated using GraphPad Prism 5.0 software (La Jolla, CA, USA).

\section{Detection of acidic vesicular organelles (AVOs)}

AVOs were detected by acridine orange (AO) staining. A549, SK-MES-1 and H661 cells were plated in a 12-well plate at a density of $1 \times 10^{5}$ cells/well and treated with BITC for $24 \mathrm{~h}$. The cells were stained with $1 \mu \mathrm{g} / \mathrm{mL}$ AO in PBS for $15 \mathrm{~min}$ at $37^{\circ} \mathrm{C}$, washed with PBS, and examined under a fluorescence microscope (Nikon, Tokyo, Japan) at ×100 magnification.

\section{Detection of LC3 puncta formation}

LC3 puncta formation was assayed by pSELECT-GFP-LC3. The transfection was carried out using Lipofectamine 2000 transfection reagent (Invitrogen, Carlsbad, CA, USA) following the manufacturer's instruction. Briefly, cells were plated in a 24-well plate at a density of $1 \times 10^{5}$ cells/well and transfected with $500 \mathrm{ng}$ of pSELECT-GFP-LC3. Twenty-four hours later, the cells were treated with BITC for another $24 \mathrm{~h}$. The punctate pattern of LC3 was observed by a fluorescence microscope at $100 \times$ magnification.

\section{Measurement of intracellular $\mathrm{Ca}^{2+}$}

Cells were seeded at a density of $3 \times 10^{5}$ cells/well in a 6-well plate. The cells were stained with $5 \mu \mathrm{mol} / \mathrm{L}$ Fluo-3-AM (DOJINDO LABORTORIES, Kumamoto, Japan) for $30 \mathrm{~min}$ at $37^{\circ} \mathrm{C}$ and then treated with BITC for $4 \mathrm{~h}$. The level of intracellular $\mathrm{Ca}^{2+}$ was detected by measuring the intensity of fluorescence using a FACSAria flow cytometer (Becton Dickinson, Franklin Lakes, NJ, USA)

\section{Western blotting analysis}

Western blot analyses were performed as previously described ${ }^{[16]}$. Briefly, cells were incubated with BITC for $24 \mathrm{~h}$ and washed with PBS, and the cell pellets were then prepared in lysis buffer [ $20 \mathrm{mmol} / \mathrm{L}$ Tris (pH 7.5), 1\% Triton X-100, 150 $\mathrm{mmol} / \mathrm{L} \mathrm{NaCl}$, sodium pyrophosphate, $\beta$-glycerophosphate, leupeptin, EDTA, and $\left.\mathrm{Na}_{3} \mathrm{VO}_{4}\right]$. The lysates were separated by SDS-PAGE and then transferred to nitrocellulose membranes. The membranes were blocked for $1 \mathrm{~h}$ at room temperature with $5 \%$ milk protein and $0.1 \%$ Tween 20 in PBS, and were then probed with the indicated antibodies at a 1:1000 dilution in $0.1 \%$ Tween 20 in PBS with 5\% BSA overnight at $4^{\circ} \mathrm{C}$. After washing, the membranes were probed with an HRP-conjugated secondary antibody at a 1:5000 dilution in $0.1 \%$ Tween 
20 in PBS with 3\% milk protein for $1 \mathrm{~h}$. The blots were developed with the Phototope-HRP Western Blot Detection system (Cell Signaling, Beverly, MA, USA).

\section{RNA interference}

Cells $\left(3 \times 10^{5}\right.$ cells/well in a 6 -well plate) were transfected with siRNA duplexes specific for the target genes at a concentration of $200 \mathrm{nmol} / \mathrm{L}$ using Lipofectamine 2000 (Invitrogen). After $6 \mathrm{~h}$, the cells were treated with BITC and incubated for another $48 \mathrm{~h}$. The expression of the target genes was examined by Western blot analysis. The sequences of a set of three siRNA duplexes for PERK were as follows: 1) Sense: 5'-GUGGAAAGGUGAGGUAUAUTT-3', anti-sense: 5'-AUAUACCUCACCUUUCCACTT-3'. 2) Sense: 5'-GUAGCUGGAAUGACAUAAATT-3', anti-sense: 5'-UUUAUGUCAUUCCAGCUACTT-3'. 3) Sense: 5'-GGAUGCACCAUCAGUUAAATT-3', anti-sense: 5'-UUUAACUGAUGGUGCAUCCTT-3'. The sequences of a set of three siRNA duplexes for ATG5 were as follows: 1) Sense: 5'-GACGUUGGUAACUGACAAATT-3', anti-sense: 5'-UUUGUCAGUUACCAACGUCTT-3'. 2) Sense: 5'-GUCCAUCUAAGGAUGCAAUTT-3', anti-sense: 5' -AUUGCAUCCUUAGAUGGACTT-3'. 3) Sense: 5'-GACCUUUCAUUCAGAAGCUTT-3', anti-sense: 5'-AGCUUCUGAAUGAAAGGUCTT-3'. The siRNA duplexes were purchased from Genepharma (Shanghai, China).

\section{Mouse tumor model and BITC treatment}

Four- to five-week-old female BALB/c nude mice were purchased from the Cancer Institute of the Chinese Academy of Medical Science (Beijing, China). The use of the mice and their care during the study were in accordance with the Tianjin Medical University Institutional Animal Care and Use Committee guidelines. The mice in this study were maintained in a climate-controlled environment with a 12-h light/12-h dark cycle with food and water. A549-luc cells (an A549 cell line expressing luciferase that was established by our laboratory) were subcutaneously injected into mice. The mice were randomly divided into two groups (five mice per group) and treated with either BITC $(100 \mathrm{mg} / \mathrm{kg})$ or PBS by intraperitoneal injection. The treatment was continued for 8 weeks. Tumor formation was detected by an IVIS Imaging System (Xenogen Corporation, Alameda, CA, USA). The tumor tissues were dissected and used for immunoblotting.

\section{Statistical analysis}

The data are presented as the mean \pm standard deviation (SD). The variance analysis between groups was performed using a one-way ANOVA. The significance of differences between the control and treatment groups was analyzed using Dunnett's multiple comparison test. Differences with a $P$-value $<0.05$ were considered statistically significant.

\section{Results}

BITC treatment inhibited lung cancer cell growth

To study the effect of BITC on lung cancer cell growth, we

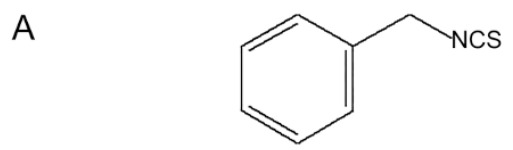

Benzylisothiocyanate, BITC
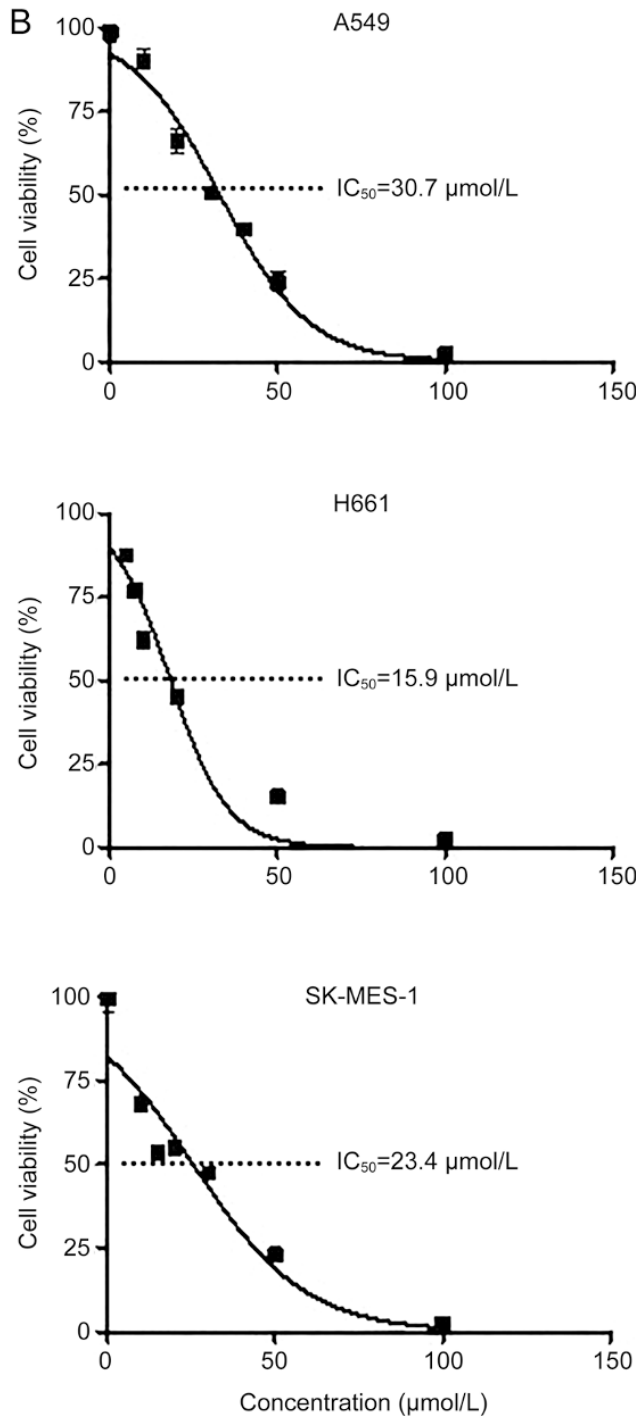

Figure 1. BITC inhibited human lung cancer cell growth. (A) Structure of benzyl isothiocyanate. (B) Cell viability of lung cancer cells. A549, H661, and SK-MES-1 cells were treated with 1-100 $\mu \mathrm{mol} / \mathrm{L} \mathrm{BITC.} \mathrm{The}$ control group was treated with vehicle (DMSO). After $48 \mathrm{~h}$, the cells were collected, and the viable cells were counted with the Cell Counting Kit-8. Values represent the mean $\pm S D$ from three independent experiments.

chose three lung cancer cell lines representing different pathological subtypes, A549 (adenocarcinoma), SK-MES-1 (squamous cell carcinoma) and H661 (large cell carcinoma). The cells were treated with 1-100 $\mathrm{mol} / \mathrm{L}$ BITC for $48 \mathrm{~h}$, and the cell viability was then assayed with a Cell Counting Kit8. There was a dose-dependent inhibition of cell growth. The 
$\mathrm{IC}_{50}$ values were $30.7 \pm 0.14 \mu \mathrm{mol} / \mathrm{L}$ for A549 cells, $15.9 \pm 0.22$ $\mu \mathrm{mol} / \mathrm{L}$ for H661 cells, and 23.4 $\pm 0.11 \mu \mathrm{mol} / \mathrm{L}$ for SK-MES-1 cells (Figure 1B). When we compared the inhibitory effect of BITC in these three cell lines, we found that the inhibitory effect of BITC was most potent in H661 cells, least potent in A549 cells, and intermediately potent in SK-MES-1 cells.

\section{BITC treatment caused autophagy in lung cancer cells}

Because many compounds may cause autophagy in different types of cells, we investigated the effect of BITC on the autophagy status of lung cancer cells. AVOs are a hallmark of autophagy. Using vital acridine orange (AO) staining, AVOs can be characterized by yellow-orange fluorescence. After being exposed to 0 to $20 \mu \mathrm{mol} / \mathrm{L}$ BITC for $24 \mathrm{~h}$, lung cancer cells were stained with $\mathrm{AO}$, and the formation of AVOs was analyzed using a fluorescence microscope. Figure 2A shows that the formation of yellow-orange AVOs was induced in all three cell lines in a dose-dependent manner and that the AVO formation was much lower in untreated cells. When we compared the basal level of autophagy in the three cell lines, we found that the highest level was observed in A549 cells and the lowest level was observed in H661 cells. The punctate pattern of LC3 is another hallmark of autophagy. Lung cancer cells were transfected with pSELECT-GFP-LC3, treated with $20 \mu \mathrm{mol} / \mathrm{L}$ BITC for $24 \mathrm{~h}$, and then observed by fluorescence microscopy. As shown in Figure 2B, all three cell lines displayed a punctate pattern of LC3 after BITC treatment compared with untreated cells.

The accumulation of LC3-II is widely used for autophagy detection, and the expression level of LC3-II represents the level of autophagy. Our Western blot results showed that BITC induced the accumulation of LC3-II in both a dose- and time-dependent manner (Figure 2C, 2D). The accumulation of LC3-II appeared as early as $4 \mathrm{~h}$ and continued accumulating up to $24 \mathrm{~h}$. The expression level of LC3-II increased with incubation time (Figure 2D). These data demonstrated that BITC induced autophagy in lung cancer cells.

\section{Autophagy played a protective role}

Autophagy plays different roles in cell survival. It may promote cell survival; it can also cause cell death. To study the precise effect of autophagy on the inhibitory effect of BITC on lung cancer cells, we applied 3-MA, a commonly used specific inhibitor of autophagy and a known class III PI3K inhibitor, to address this question. First, we detected the inhibitory effect of 3-MA on BITC-mediated autophagy induction. After $2 \mathrm{~h}$ of pretreatment with 3-MA followed by BITC exposure, we found that the formation of AVOs in lung cancer cells was decreased (Figure 3A), the punctate pattern of LC3 was attenuated (Figure 3B), and the induction of LC3-II was inhibited (Figure 3C). These data indicated that 3-MA effectively inhibited the autophagy induced by BITC. To determine whether the increased expression of LC3-II is due to the production versus the accumulation of autophagosomes, we applied another autophagy inhibitor, chloroquine (CQ), which blocks the transition of autophagosomes to autolysosomes. Cells were pre-incubated with CQ for $1 \mathrm{~h}$ and then treated with BITC. Our data showed that cells treated with CQ did exhibit an increased expression level of LC3-II, demonstrating that the increase in LC3-II is caused by the production and not the accumulation of autophagosomes (Figure 3D).

Next, we determined the role of autophagy in the growth inhibitory effect of BITC. First, we inhibited autophagy using 3-MA. As shown in Figure 3E, the suppression of autophagy by 3-MA enhanced the growth inhibitory effect of BITC. Because ATG5 plays an important role in autophagy, we further silenced ATG5 by RNAi technology in A549 cells. When ATG5 was knocked down, the LC3-II level was decreased, and the inhibitory effect of BITC was increased (Figure 3F, 3G). Taken together, these results demonstrated that autophagy plays a protective role against the growth inhibitory effect of BITC in lung cancer cells.

\section{BITC treatment induced endoplasmic reticulum stress}

Accumulating evidence indicates that ER stress pathways are evoked by anticancer agents. To elucidate whether ER stress is involved in the inhibitory effect of BITC, we assessed the ER stress condition in lung cancer cells. One of the markers of ER stress is an increase in the cytosolic calcium level. The effect of BITC on the $\mathrm{Ca}^{+}$level in A549, H661, and SK-MES-1 cells was detected by flow cytometry using Fluo-3-AM. The $\mathrm{Ca}^{+}$levels in the lung cancer cells were markedly increased by BITC in a dose-dependent manner compared with DMSO treatment. When we compared the basal level of $\mathrm{Ca}^{+}$in the three cell lines, we found that the basal level of $\mathrm{Ca}^{+}$was highest in H661 cells and lowest in A549 cells (Figure 4A). PERK plays a central role in the ER stress response. When PERK is activated under ER stress, it phosphorylates and activates its target gene eIF2a. In our study, as shown in Figure 4B, the phospho-PERK levels in lung cancer cells were increased after BITC treatment, and the phospho-eIF2a levels were elevated accordingly. These results indicated that BITC induced ER stress in lung cancer cells.

\section{ER stress mediated the autophagy induction by BITC}

Many studies have indicated that ER stress is an inducer of autophagy. This drove us to evaluate whether ER stress mediates the autophagy induction by BITC. We manipulated the ER stress response using 4-PBA, an ER stress-specific inhibitor. As shown in Figure 4B, when ER stress was activated by BITC, autophagy occurred simultaneously, as indicated by LC3-II accumulation. When lung cancer cells were pretreated with 5 $\mathrm{mmol} / \mathrm{L}$ 4-PBA for $2 \mathrm{~h}$, the PERK phosphorylation level was suppressed, while the LC3-II level was decreased. To further explore the effect of 4-PBA on autophagy, we assessed the formation of AVOs and the punctate pattern of LC3. As depicted in Figure 5A, $2 \mathrm{~h}$ of pretreatment with 4-PBA resulted in a markedly reduced formation of AVOs, and the punctate pattern of LC3 was also attenuated (Figure 5B). Because PERK is a key component in the ER stress response, we knocked down PERK by RNA interference technology. Figure 5C shows that PERK knockdown reduced the expression levels of both 
A

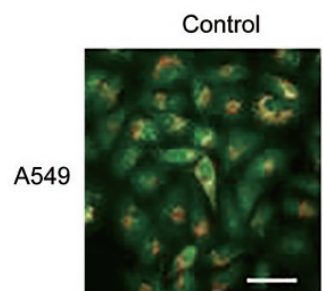

BITC $(10 \mu \mathrm{mol} / \mathrm{L})$
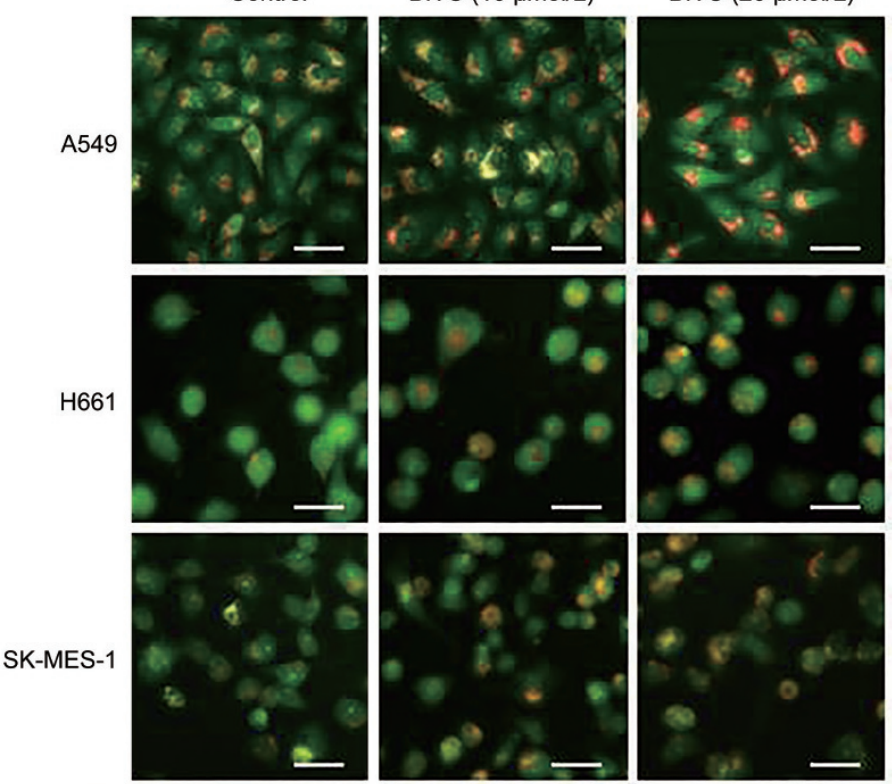

C
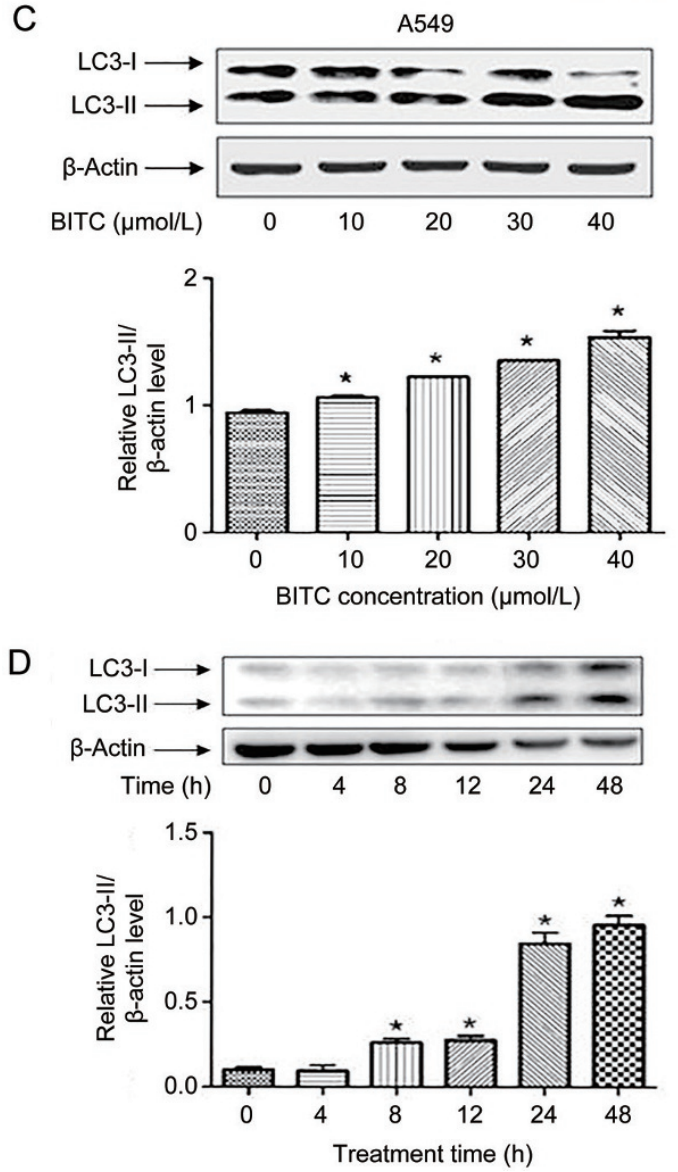
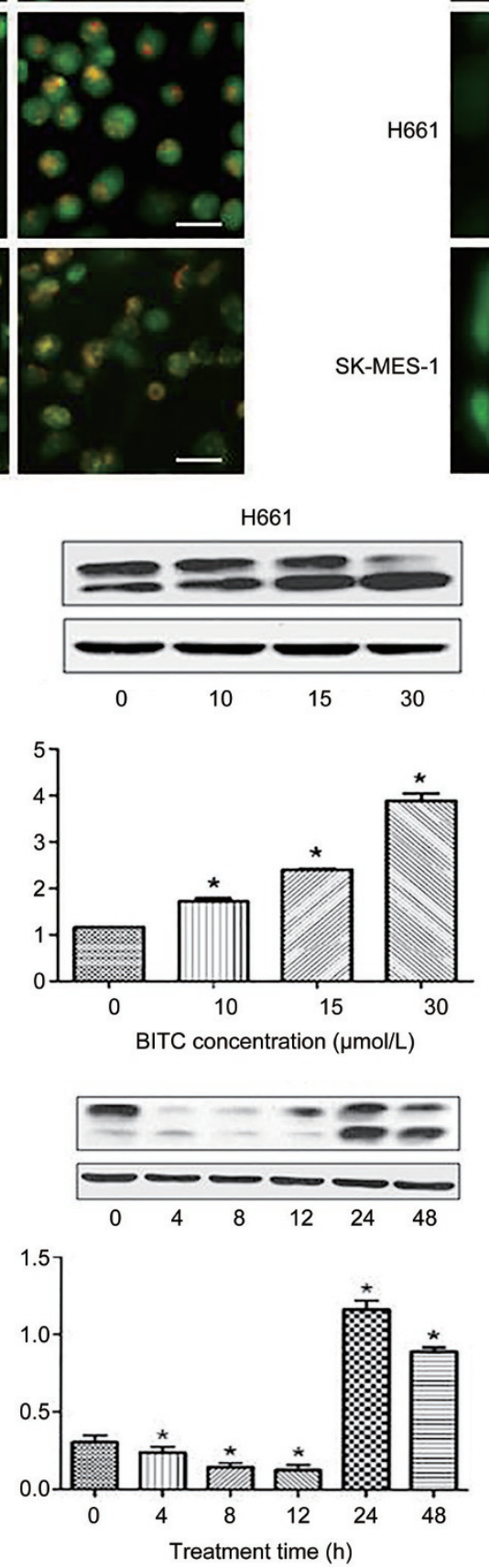

Control
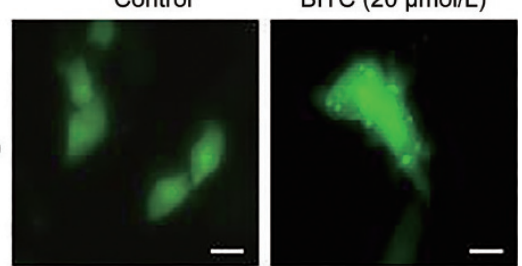

SK-MES-1
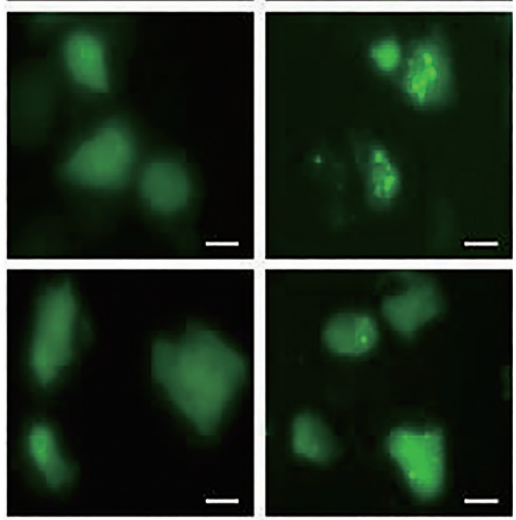

SK-MES-1
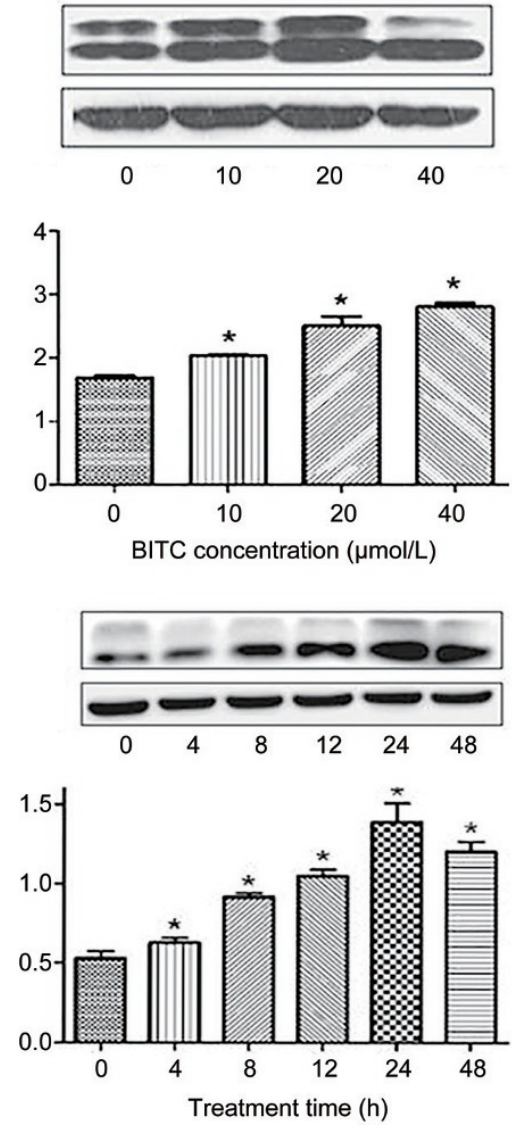

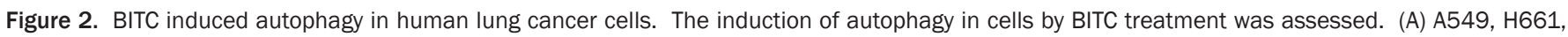

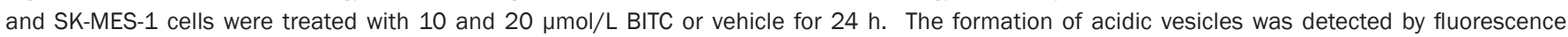

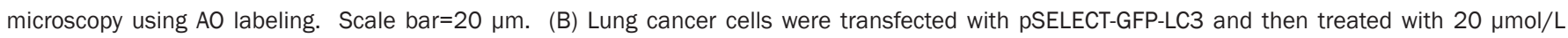

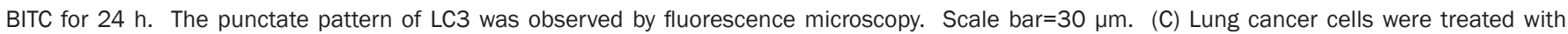

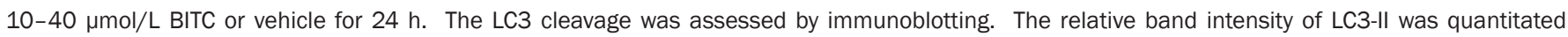

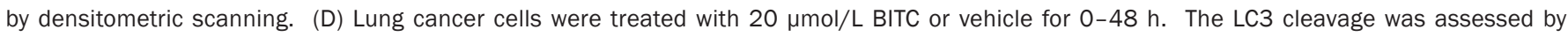

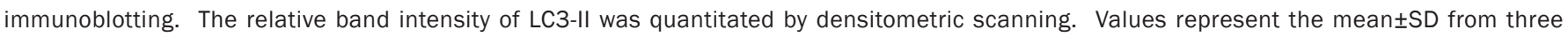
independent experiments. Columns, mean; bars, SD. ${ }^{*} P<0.05$. 
A

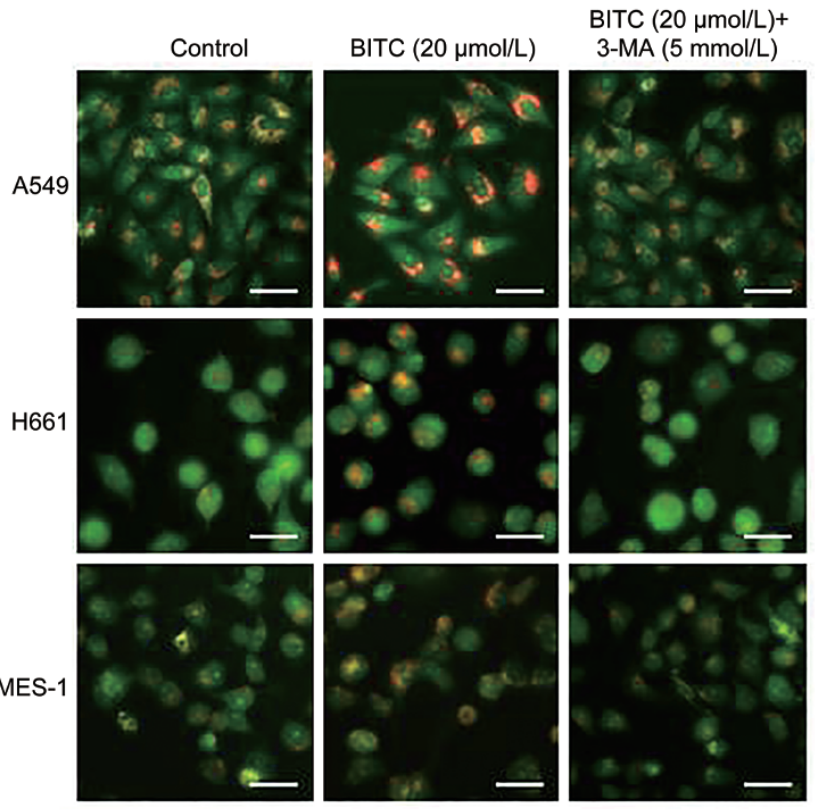

B
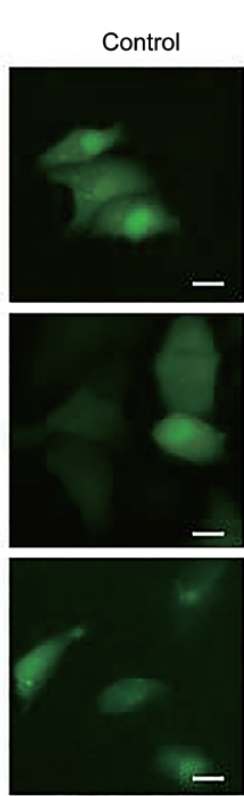

H661
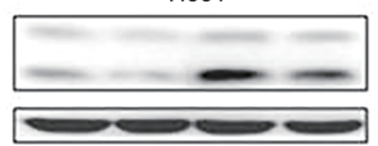

BITC $(20 \mu \mathrm{mol} / \mathrm{L})+$ 3-MA (5 mmol/L)
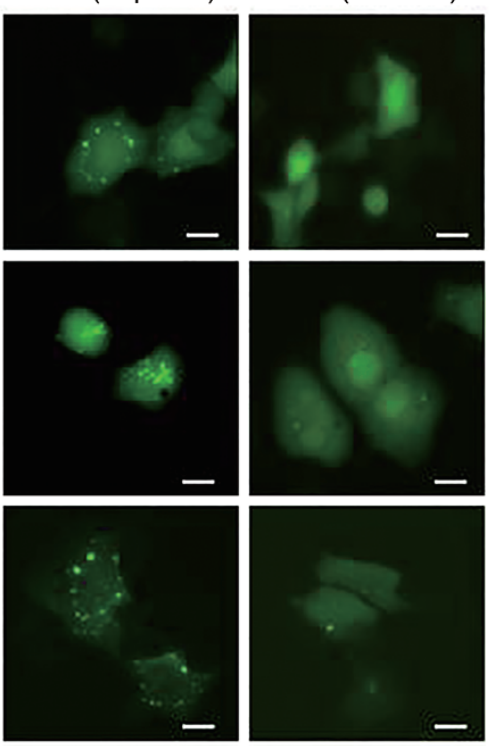

C
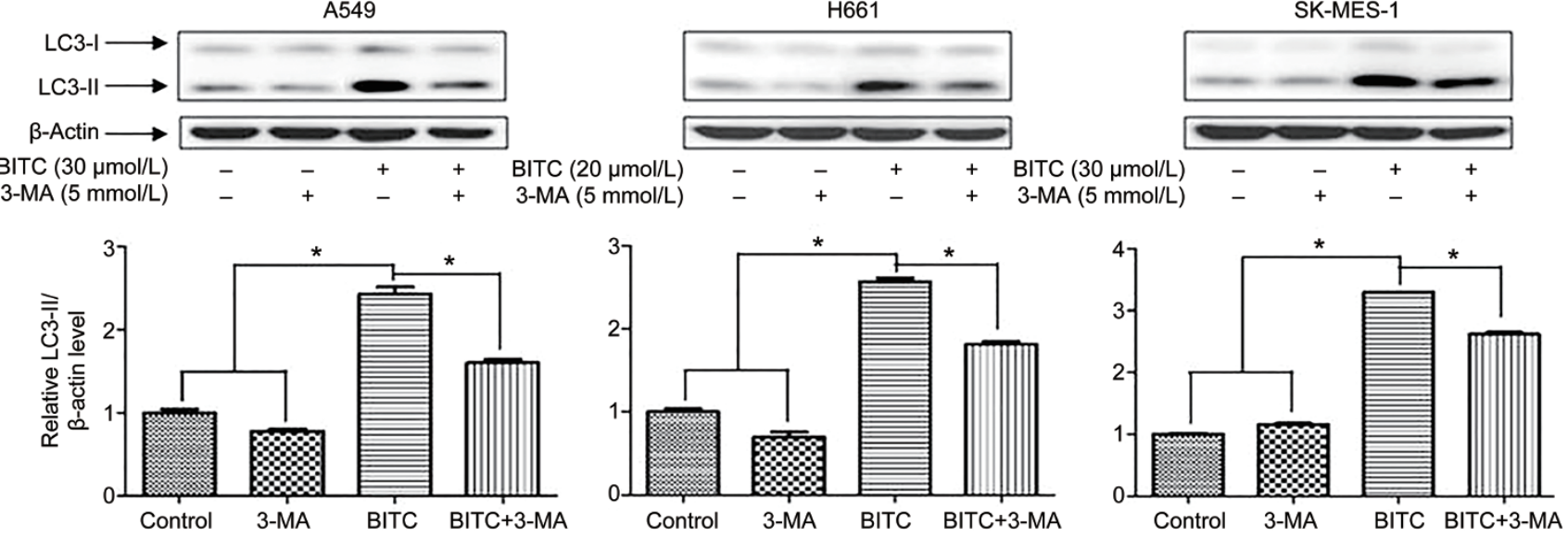

D

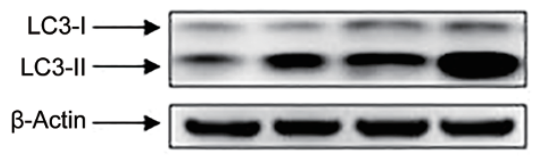

$\operatorname{BITC}(30 \mu \mathrm{mol} / \mathrm{L}) \quad-\quad-\quad+\quad+\operatorname{BITC}(20 \mu \mathrm{mol} / \mathrm{L})$

$\mathrm{CQ}(5 \mu \mathrm{mol} / \mathrm{L})+\ldots+\quad+\quad \mathrm{CQ}(5 \mu \mathrm{mol} / \mathrm{L})$
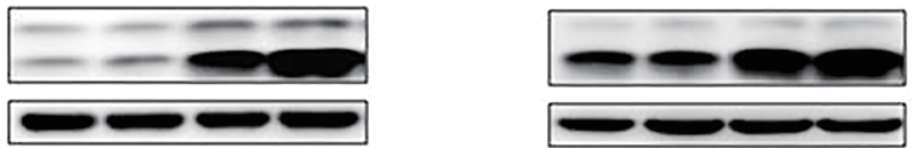

$\mathrm{BITC}(30 \mu \mathrm{mol} / \mathrm{L})$
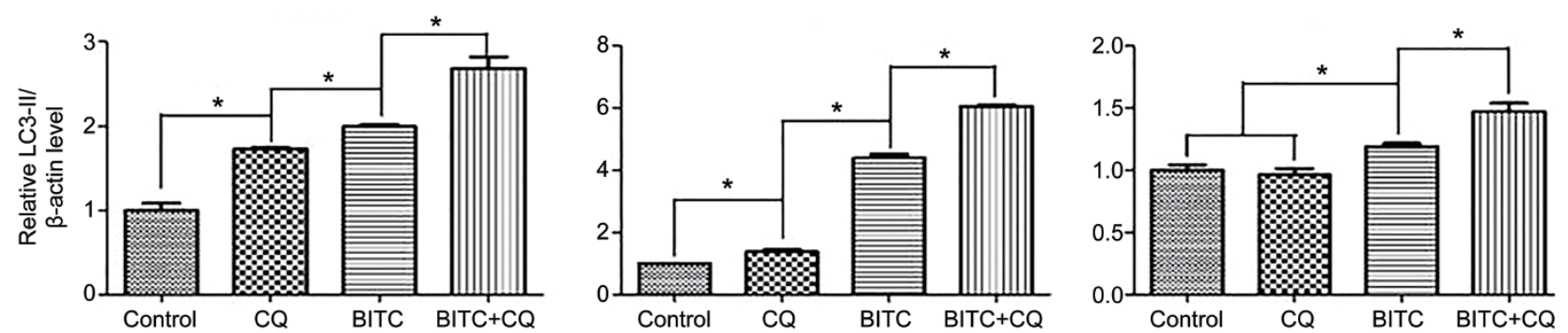

Figure 3A-3D. Inhibition of autophagy enhanced the inhibitory effect of BITC on human lung cancer cells. (A) Lung cancer cells were pretreated with 5 $\mathrm{mmol} / \mathrm{L} 3-\mathrm{MA}$ for $2 \mathrm{~h}$ and then exposed to $20 \mu \mathrm{mol} / \mathrm{L}$ BITC or vehicle for $24 \mathrm{~h}$. The formation of acidic vesicles was detected by fluorescence microscopy using AO labeling. Scale bar=20 $\mu \mathrm{m}$. (B) Lung cancer cells were transfected with pSELECT-GFP-LC3. After $2 \mathrm{~h}$ of pretreatment with 5 mmol/L 3-MA, the cells were treated with $20 \mu \mathrm{mol} / \mathrm{L}$ BITC for $24 \mathrm{~h}$. The punctate pattern of LC3 was observed by fluorescence microscopy. Scale bar=30 $\mu \mathrm{m}$. (C) Lung cancer cells were pretreated with 5 mmol/L 3-MA for $2 \mathrm{~h}$ and then treated with 20 or $30 \mu \mathrm{mol} / \mathrm{L}$ BITC or vehicle for $24 \mathrm{~h}$. The LC3 cleavage was assessed by immunoblotting. (D) Lung cancer cells were pretreated with 0 or $5 \mu \mathrm{mol} / \mathrm{L} \mathrm{CQ}$ for $1 \mathrm{~h}$ and then treated with 20 or $30 \mu \mathrm{mol} / \mathrm{L}$ BITC or vehicle for $24 \mathrm{~h}$. The LC3 cleavage was assessed by immunoblotting. 
$\mathrm{E}$

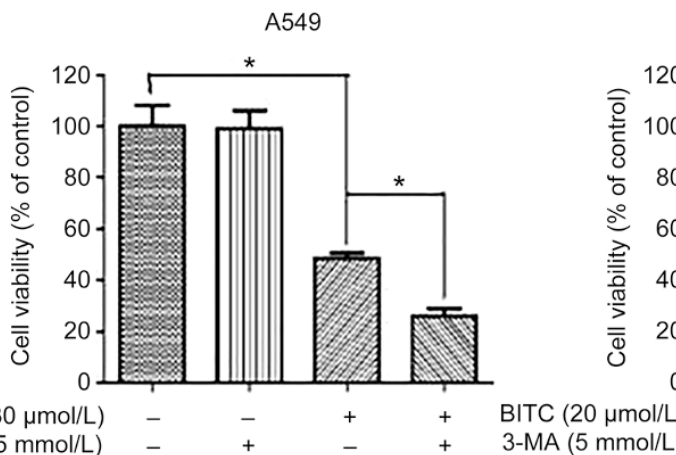

$\mathrm{F}$

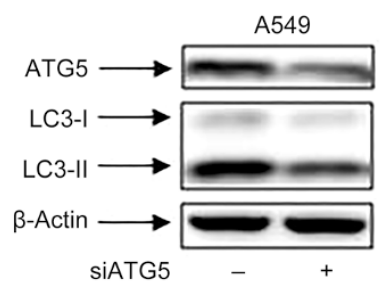

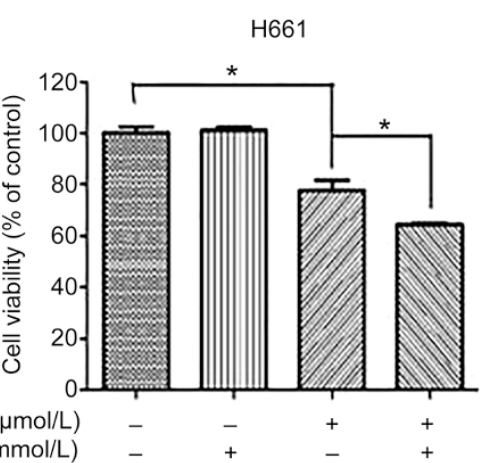

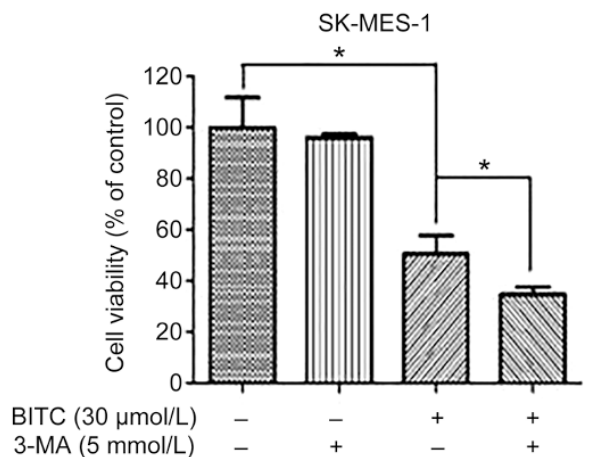

G

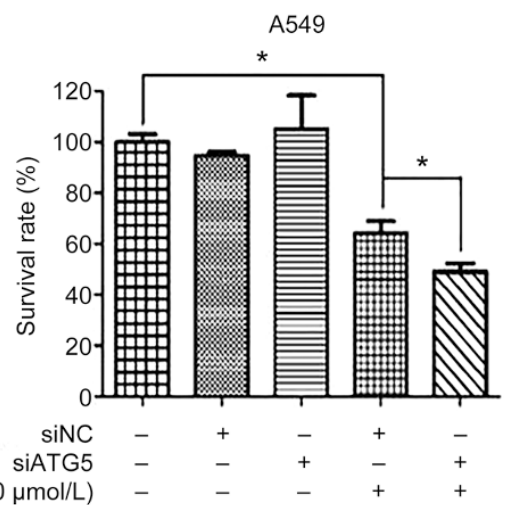

Figure 3E-3G. (E) Lung cancer cells were pretreated with $5 \mathrm{mmol} / \mathrm{L}$ 3-MA for $2 \mathrm{~h}$ and then exposed to 20 or $30 \mu \mathrm{mol} / \mathrm{L}$ BITC or vehicle for $24 \mathrm{~h}$. The viable cells were counted. (F) The expression of ATG5 was knocked down using RNAi technology. The levels of ATG5 were analyzed by immunoblotting. (G) The expression of ATG5 was knocked down using RNAi, and the cells were then treated with $30 \mu \mathrm{mol} / \mathrm{L}$ BITC for $48 \mathrm{~h}$. The viable cells were counted. Values represent the mean \pm SD from three independent experiments. Columns, mean; bars, SD. ${ }^{*} P<0.05$.

phospho-eIF2a and LC3-II. Using 4-PBA treatment and PERK knockdown experiments, we demonstrated that the inhibition of ER stress suppressed autophagy induction.

Because our previous results showed that autophagy played a protective role in cell growth in this study, we next detected the effect of 4-PBA on cell growth. Figure 5D indicates that due to suppressing ER stress and autophagy, 4-PBA further enhanced the inhibitory effect of BITC on cell growth. These data confirmed that the inhibition of ER stress suppresses the induction of protective autophagy. Taken together, our results strongly suggested that BITC induces protective autophagy in lung cancer cells through the ER stress response.

\section{BITC inhibited A549 xenograft growth and induced autophagy and ER stress}

In vivo studies are crucial for the investigation of anticancer agents; therefore, we designed animal experiments to evaluate whether BITC treatment inhibits lung tumor growth and causes autophagy. The body weights of control and BITCtreated mice were not significantly different throughout the experimental procedure (data not shown). Using in vivo imaging technology, we found that the average tumor signal of BITC-treated mice was $69.2 \%$ less than that of the control mice (Figure 6A, 6B). This result indicated that BITC effectively inhibited lung tumor growth in vivo. Next, we investigated the autophagy and ER stress status in tumors. The tumor tissues were dissected, and markers of autophagy and ER stress were detected by immunoblotting. There was a significant increase in the expression of the autophagy marker LC3-II, which indicated the elevated level of autophagy in the tumor tissues. Furthermore, the expression of the ER stress-related proteins PERK, eIF2a, and phospho-eIF2a were all increased, as shown in Figure 6C. These results demonstrated that the BITC-mediated suppression of A549 xenograft growth in vivo was accompanied by autophagy and ER stress.

\section{Discussion}

Our previous studies showed that BITC, PEITC and AITC inhibit leukemia and lung cancer cell growth ${ }^{[10,13,14,17-19]}$. Numerous studies have also reported that BITC inhibits many other types of cancer cell growth, such as breast cancer ${ }^{[11]}$, prostate cancer ${ }^{[12]}$, and glioma ${ }^{[20]}$. Although mechanistic studies have shown that the anticarcinogenic activity of BITC may be due to the induction of apoptosis or cell cycle arrest, increased oxidative stress, or interference with cell survival signaling pathways, the precise underlying mechanism is not fully understood ${ }^{[9]}$.

The present study provides the first evidence of autophagy induction by BITC in human lung cancer cells. Autophagy is a dynamic recycling system. The cytoplasmic materials 


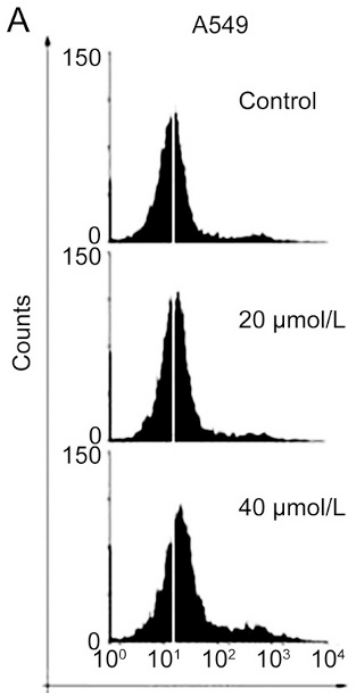

Fluo-3-AM

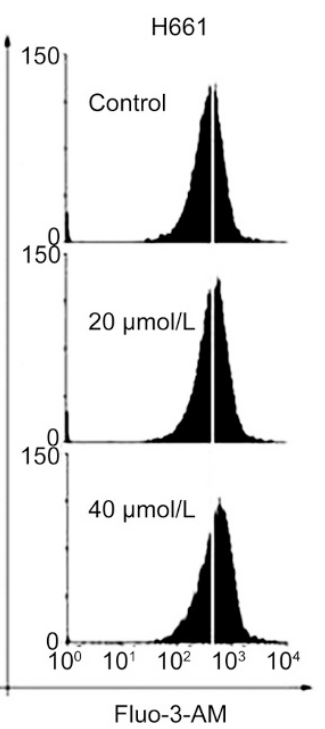

Fluo-3-AM

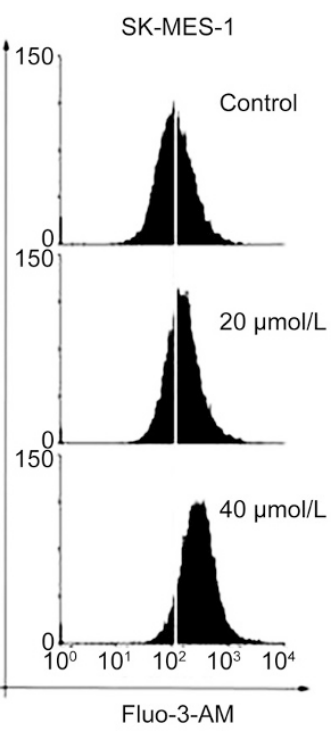

Fluo-3-AM

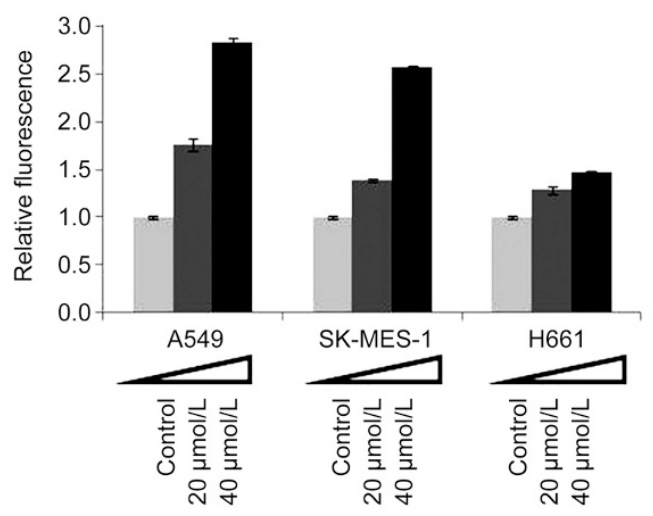

B

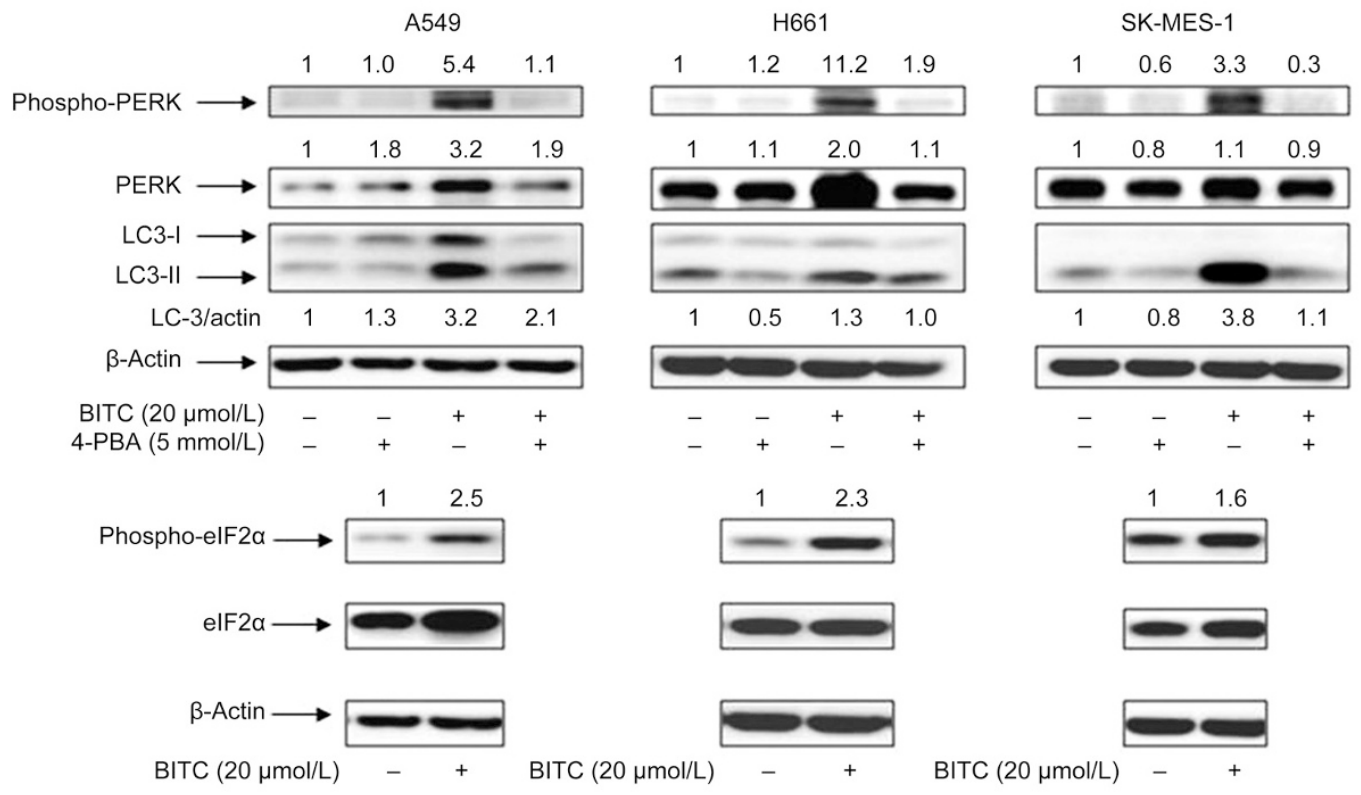

Figure 4. BITC activated ER stress in human lung cancer cells. The ER stress induced by BITC treatment was assessed. (A) Lung cancer cells were labeled with $5 \mu \mathrm{mol} / \mathrm{L}$ Fluo-3-AM for $30 \mathrm{~min}$ at $37^{\circ} \mathrm{C}$ and then treated with $20-40 \mu \mathrm{mol} / \mathrm{L} \mathrm{BITC}$ for $4 \mathrm{~h}$. The level of intracellular Ca ${ }^{2+}$ was detected by measuring the intensity of fluorescence using flow cytometry. (B) Lung cancer cells were pretreated with $5 \mathrm{mmol} / \mathrm{L} 4$-PBA for $2 \mathrm{~h}$ and then treated with $20 \mu \mathrm{mol} / \mathrm{L}$ BITC or vehicle for $24 \mathrm{~h}$. The levels of p-PERK, PERK, p-elF2 $\alpha$, elF2 $\alpha$, LC3-I, and LC3-II were analyzed by immunoblotting. Values represent the mean $\pm \mathrm{SD}$ from three independent experiments. Columns, mean; bars, SD.

are degraded in the lysosome to produce new materials and energy for cell survival and renovation ${ }^{[3]}$. Recent studies have shown that isothiocyanates induce autophagy in cancer cells. In breast cancer cells, BITC induces autophagic death via the FoxO1 pathway ${ }^{[21]}$. In pancreatic cancer cells, although SFN causes autophagy, the modulation of autophagy by the autophagy inhibitor chloroquine or inducer rapamycin did not alter SFN-mediated cytotoxicity ${ }^{[22]}$. However, the induction of autophagy in lung cancer cells by BITC has not been reported.

In the present study, by monitoring the formation of AVOs and the punctate pattern of LC3 and detecting the autophagy marker proteins LC3-II and ATG5 in BITC-treated lung cancer cells, we reveal that BITC induces autophagy in human lung cancer cells. The lung cancer cells we tested represent different pathological subtypes of lung cancer, including adenocarcinoma (A549 cells), squamous cell carcinoma (SK-MES-1 cells), and large cell carcinoma (H661 cells), giving our findings a more meaningful clinical significance.

Autophagy plays dual roles in cancer, acting as either a tumor suppressor or a tumor promoter. The autophagy induced by anticancer agents also plays controversial roles. Some agents induce pro-death autophagy. 6-Shogaol inhibits 
A

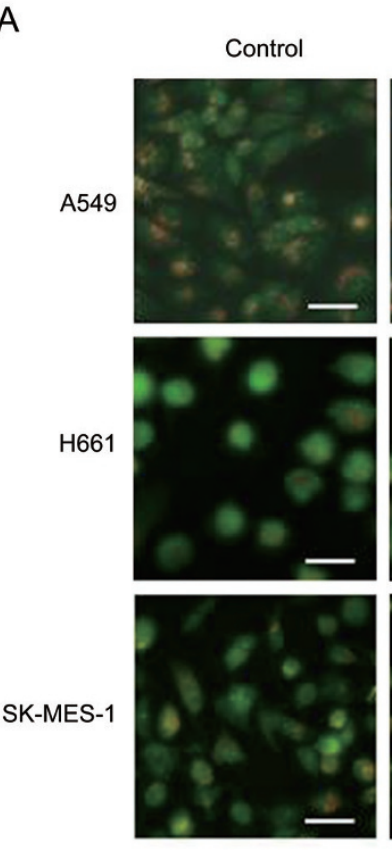

C

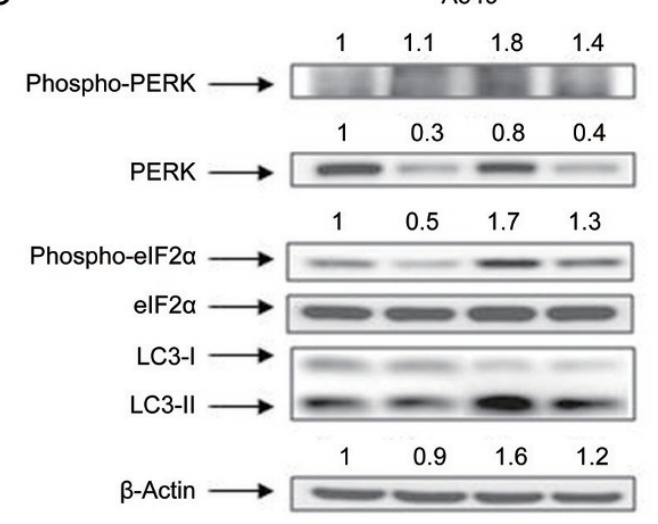

BITC $(20 \mu \mathrm{mol} / \mathrm{L})+$ BITC $(20 \mu \mathrm{mol} / \mathrm{L})$
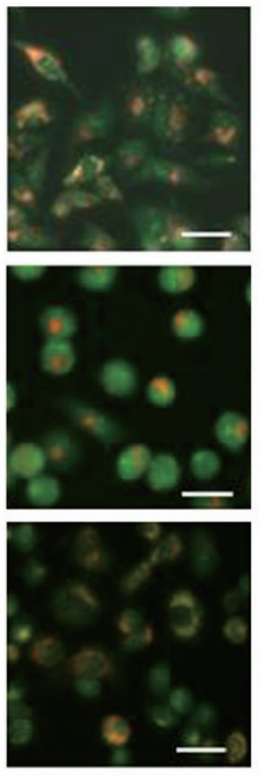
4-PBA (5 mmol/L)
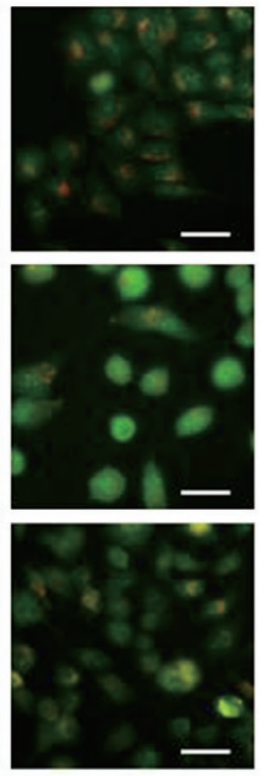

B

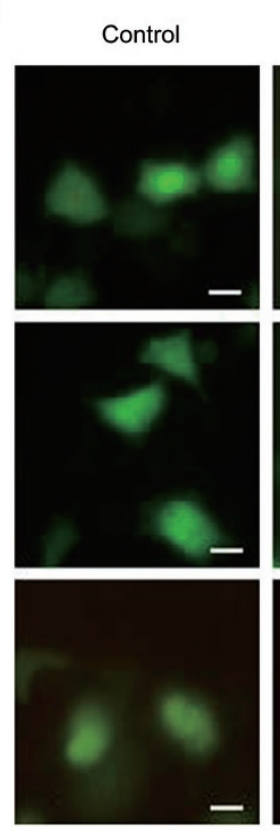

BITC $(20 \mu \mathrm{mo} / \mathrm{L})+$

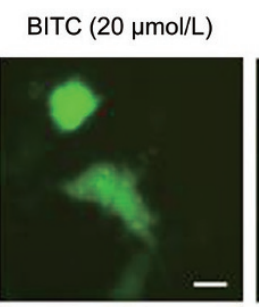
4-PBA (5 mmol/L)
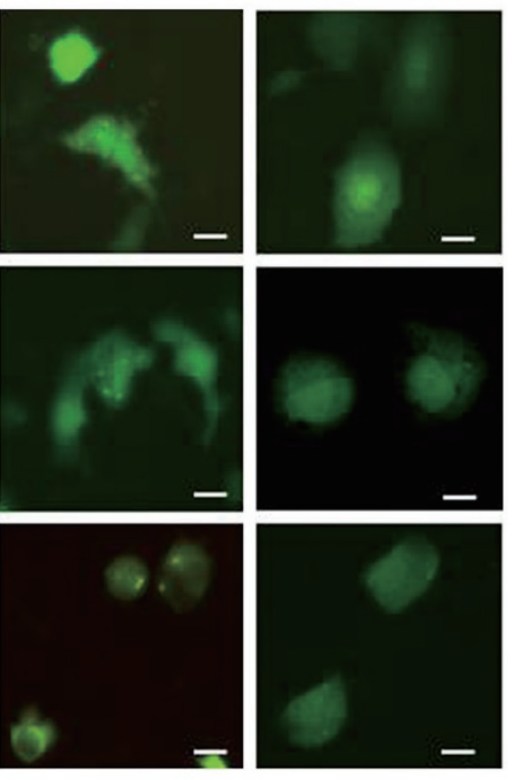

H661

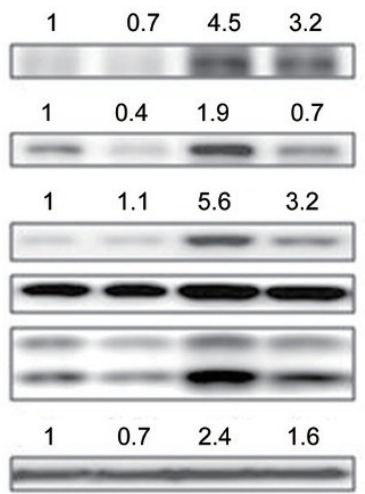

SK-MES-1

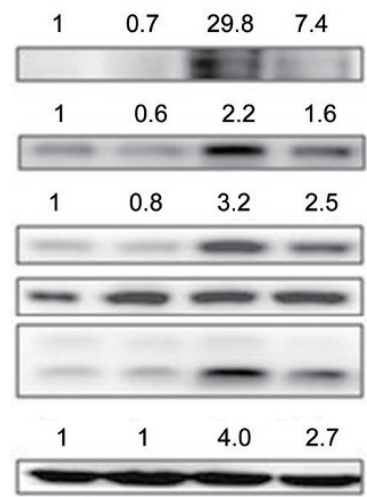

$\mathrm{BITC}(20 \mu \mathrm{mol} / \mathrm{L})$ SIPERK - + + +
D

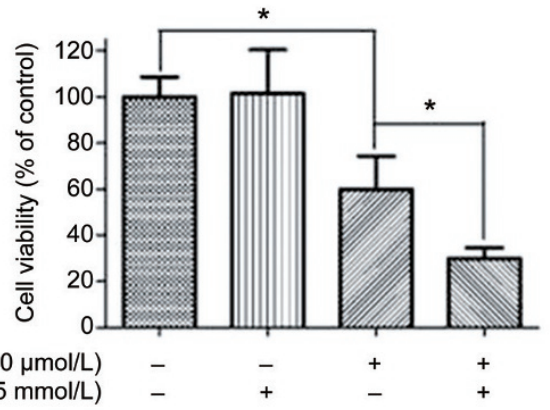

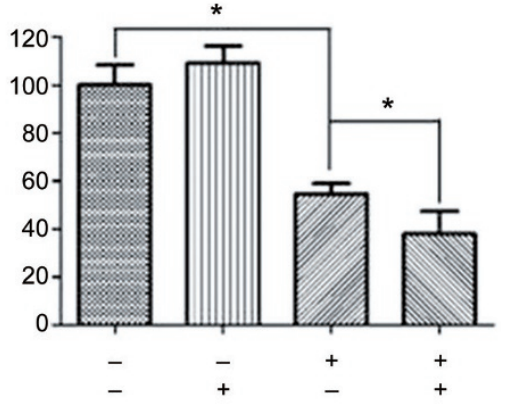

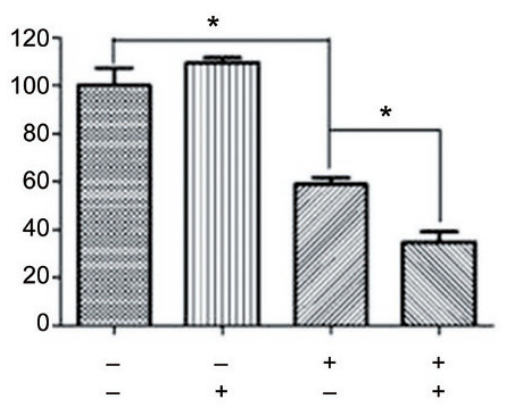

Figure 5. ER stress mediated the autophagy induction by BITC. (A) Lung cancer cells were pretreated with $5 \mathrm{mmol} / \mathrm{L} 4-\mathrm{PBA}$ for $2 \mathrm{~h}$ and then exposed to $20 \mu \mathrm{mol} / \mathrm{L}$ BITC or vehicle for $24 \mathrm{~h}$. The formation of acidic vesicles was detected by fluorescence microscopy using AO labeling. Scale bar=20 $\mu \mathrm{m}$. (B) Lung cancer cells were transfected with pSELECT-GFP-LC3. After $2 \mathrm{~h}$ of pretreatment with $5 \mathrm{mmol} / \mathrm{L} 4$-PBA, the cells were treated with $20 \mu \mathrm{mol} / \mathrm{L}$ BITC for $24 \mathrm{~h}$. The punctate pattern of LC3 was observed by fluorescence microscopy. Scale bar=30 $\mu \mathrm{m}$. (C) The cellular PERK expression was knocked down using RNA interference technology. The cells were then treated with 20-30 $\mu \mathrm{mol} / \mathrm{L}$ BITC for $24 \mathrm{~h}$. The levels of p-PERK, PERK, p-elF2 $\alpha$, elF2 $\alpha$, LC3-1, and LC3-II were analyzed by immunoblotting. 
A
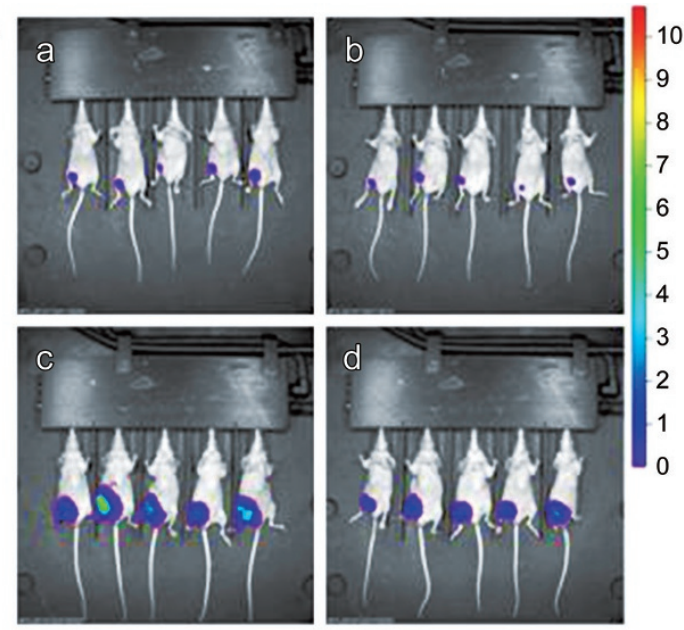

C

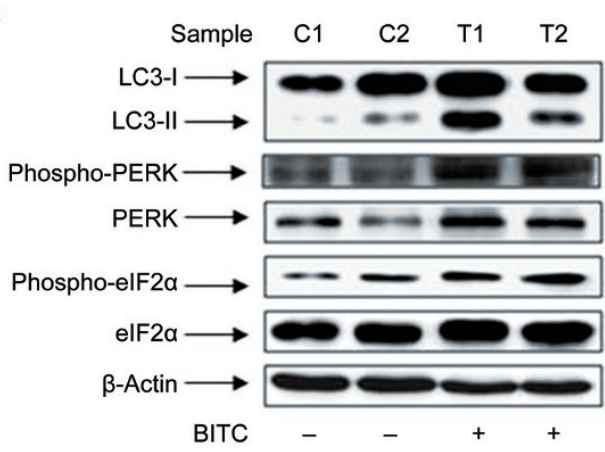

B
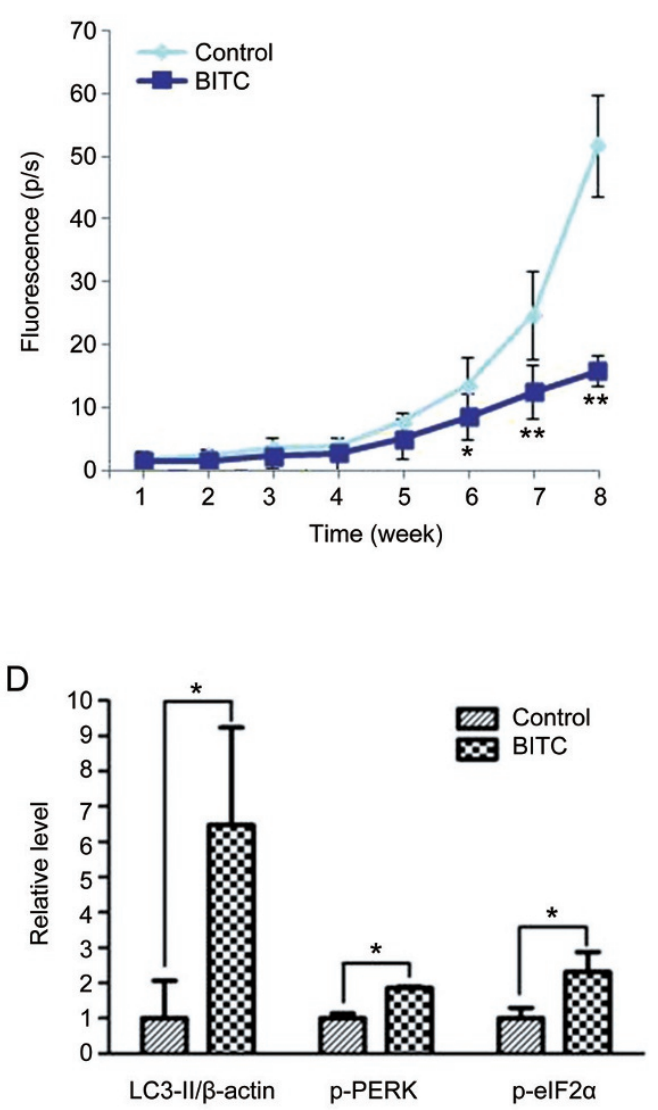

Figure 6. BITC inhibited tumor growth and induced autophagy in vivo. (A, B) A549-luc cells were subcutaneously injected into mice. The treatment was continued for 8 weeks. Tumors that formed from week 1 to week 8 were detected by an IVIS Imaging System. (a) and (b), control and BITC treatment groups at week 1. (c) and (d), control and BITC treatment groups at week 8. (C) Tumor tissues from two different mice in each group were used for immunoblot analysis. The relative band intensity was quantitated by densitometric scanning. $\mathrm{C} 1$ and $\mathrm{C} 2$, control group; T1 and T2, treatment group. Columns, mean; bars, SD. ${ }^{*} P<0.05,{ }^{* *} P<0.01$ vs control.

breast cancer cell growth and induces autophagic cell death by modulating the Notch signaling pathway ${ }^{[23]}$. An andrographolide analog induces autophagy-mediated cell death in leukemia cells by inhibiting the PI3K/Akt/mTOR pathway ${ }^{[24]}$. SZC017, a novel oleanolic acid derivative, induces apoptosis and autophagy in human breast cancer cells via the oxidative stress pathway ${ }^{[25]}$. However, anticancer agents may induce cytoprotective autophagy. A study by Viola $\mathrm{G}$ et al shows that a new tubulin inhibitor, MG-2477, induces autophagy through the inhibition of the Akt/mTOR pathway and delays apoptosis in lung cancer cells ${ }^{[26]}$. The PI3K/mTOR inhibitor NVPBEZ235 suppresses breast cancer cell growth. The inhibition of autophagy increases the proliferation inhibition and apoptosis induction mediated by NVP-BEZ235 ${ }^{[27]}$. The combinational treatment of gefitinib and chloroquine, an autophagy inhibitor, can overcome the acquired drug resistance in hepatoma carcinoma cells ${ }^{[28]}$. Hwang et al reported that the inhibition of autophagy enhances pemetrexed- and simvastatin-induced apoptotic cell death in malignant mesothelioma and non-small cell lung cancer cells ${ }^{[29]}$.
To understand the precise role of autophagy in BITC-treated lung cancer cells, we used 3-MA, a specific autophagy inhibitor. Pretreatment with 3-MA reduced the AO-stained acidic vesicles, the formation of the punctate pattern of $\mathrm{LC} 3$, and the accumulated LC3-II protein in BITC-treated cells, and more importantly, it enhanced the inhibitory effect of BITC on lung cancer cell growth. Because ATG5 plays an important role in autophagy, we also knocked down the expression of ATG5. The silencing of ATG5 also enhanced the inhibitory effect of BITC on cell growth. These data indicated that autophagy plays a cytoprotective role in our experimental model.

The molecular mechanisms that regulate autophagy are not fully understood. The ER is a central intracellular organelle in the secretory pathway. It is responsible for protein folding, protein translocation, and protein post-translational modifications. ER stress is a collective name for perturbations in ER functions. It is a common feature triggered by a variety of conditions ${ }^{[30,31]}$. In cancer, ER stress plays a very important role. Low oxygen supply, poor vascularization, nutrient deprivation and acidic $\mathrm{pH}$ may activate ER stress. ER stress 
exerts a cytoprotective role, assisting the folding of new proteins necessary for tumor growth. However, when ER stress becomes too severe or prolonged, the pro-survival function turns into a toxic signal, causing tumor cell death ${ }^{[30,32]}$.

In recent years, research has suggested that the ER stress response is linked to the autophagic response. ER stress may mediate autophagy induction ${ }^{[33,34]}$. Accumulating evidence suggests that autophagy induction by some anticancer agents is mediated by ER stress. Saxifragifolin D, an oleananetype pentacyclic triterpenoid, induces autophagy in breast cancer through ROS-dependent ER stress ${ }^{[35]}$. a-Solanine is a glycoalkaloid, and it has been shown to induce ROS-mediated autophagy in a panel of human cancer cell lines through the activation of ER stress ${ }^{[36]}$. Lipopolysaccharide induces autophagic cell death through PERK-dependent ER stress in human lung cancer cells ${ }^{[37]}$. These findings prompted us to explore the ER stress status in BITC-treated lung cancer cells. The ER lumen is the main storage site of $\mathrm{Ca}^{2+}$. When $\mathrm{Ca}^{2+}$ traffics into and out of the ER, it regulates diverse cellular responses and signal pathways responding to stress, including autophagy ${ }^{[30]}$. Studies have shown that when $\mathrm{Ca}^{2+}$ is released from the ER, it stimulates a CamKK/AMPK-dependent pathway that inhibits mTOR from further inducing autophagy ${ }^{[38,39]}$. We detected the levels of $\mathrm{Ca}^{2+}$, phospho-PERK and phospho-eIF2 $\mathrm{a}$, which are characteristic of ER stress. Our results indicate that BITC causes ER stress in lung cancer cells. Further experiments using the ER stress inhibitor 4-PBA and knockdown of PERK showed that the inhibition of ER stress attenuates autophagy induction by BITC and potentiates the inhibitory effect of BITC on lung cancer cell growth. Taken together, our data demonstrate that BITC-induced cytoprotective autophagy is mediated by ER stress through the PERK-eIF2a pathway (Scheme 1).

In conclusion, our study demonstrates that BITC inhibits human lung cancer cell growth and simultaneously induces autophagy in lung cancer cells, and this autophagy plays a cytoprotective role. Further investigation into the mechanism revealed that the activation of ER stress mediates the autophagy induction by BITC. Isothiocyanates are well-known anticarcinogenic agents. Our data reveal a novel mechanism for the chemotherapeutic property of BITC, and this may provide valuable information for its future application in cancer therapy.

\section{Acknowledgements}

This work was supported by the National Natural Science Foundation of China (№ 81372519), the Specialized Research Fund for the Doctoral Program of Higher Education of China (№ 20131202110005) and the Key Project of Tianjin Municipal Science and Technology Commission (№ 14JCZDJC33800).

\section{Author contribution}

Qi-cheng ZHANG, Zhen-hua PAN, and Bo-ning LIU performed the experiments; Zhao-wei MENG, Xiang WU, and Qing-hua ZHOU were involved in data interpretation; Ke XU analyzed the data and wrote the manuscript. All authors read

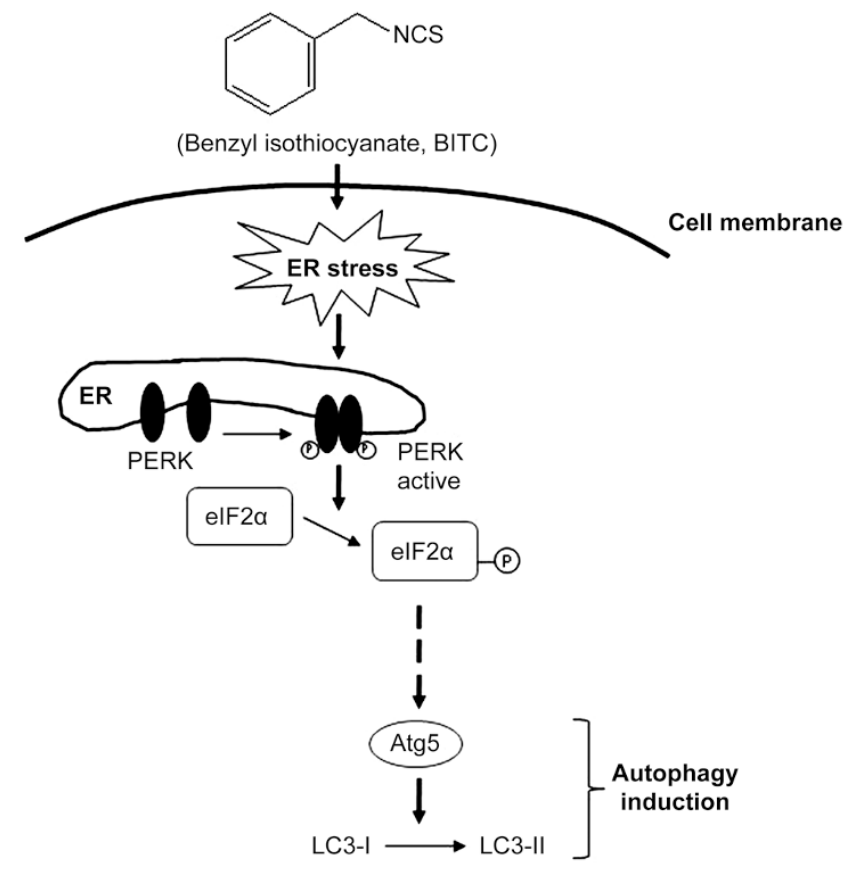

Scheme 1. A proposed model of ER stress-mediated induction of autophagy by BITC in lung cancer cells.

and approved the final manuscript.

\section{References}

1 Ferlay J, Soerjomataram I, Dikshit R, Eser S, Mathers C, Rebelo M, et al. Cancer incidence and mortality worldwide: Sources, methods and major patterns in GLOBOCAN 2012. Int J Cancer 2015; 136 : E35986.

2 DeSantis CE, Lin CC, Mariotto AB, Siegel RL, Stein KD, Kramer JL, et al. Cancer treatment and survivorship statistics, 2014. CA Cancer J Clin 2014; 64: 252-71.

3 Mizushima N, Komatsu M. Autophagy: renovation of cells and tissues. Cell 2011; 147: 728-41.

4 Choi AM, Ryter SW, Levine B. Autophagy in human health and disease. N Engl J Med 2013; 368: 1845-6.

5 White E. Deconvoluting the context-dependent role for autophagy in cancer. Nat Rev Cancer 2012; 12: 401-10.

6 Yang ZJ, Chee CE, Huang S, Sinicrope FA. The role of autophagy in cancer: therapeutic implications. Mol Cancer Ther 2011; 10: 153341.

7 Singh SV, Singh K. Cancer chemoprevention with dietary isothiocyanates mature for clinical translational research. Carcinogenesis 2012; 33: 1833-42.

8 Gupta P, Kim B, Kim SH, Srivastava SK. Molecular targets of isothiocyanates in cancer: recent advances. Mol Nutr Food Res 2014; 58: 1685-707.

9 Wu X, Zhou QH, Xu K. Are isothiocyanates potential anti-cancer drugs? Acta Pharmacol Sin 2009; 30: 501-12.

$10 \mathrm{Xu} \mathrm{K}$, Thornalley PJ. Studies on the mechanism of the inhibition of human leukaemia cell growth by dietary isothiocyanates and their cysteine adducts in vitro. Biochem Pharmacol 2000; 60: 221-31.

11 Sehrawat A, Kim SH, Vogt A, Singh SV. Suppression of FOXQ1 in benzyl isothiocyanate-mediated inhibition of epithelial-mesenchymal transition in human breast cancer cells. Carcinogenesis 2013; 34: 
864-73.

12 Lin JF, Tsai TF, Liao PC, Lin YH, Lin YC, Chen HE, et al. Benzyl isothiocyanate induces protective autophagy in human prostate cancer cells via inhibition of mTOR signaling. Carcinogenesis 2013; 34: 406-14.

13 Liu BN, Yan HQ, Wu X, Pan ZH, Zhu Y, Meng ZW, et al. Apoptosis induced by benzyl isothiocyanate in gefitinib-resistant lung cancer cells is associated with Akt/MAPK pathways and generation of reactive oxygen species. Cell Biochem Biophys 2013; 66: 81-92.

14 Wu X, Zhu Y, Yan H, Liu B, Li Y, Zhou Q, et al. Isothiocyanates induce oxidative stress and suppress the metastasis potential of human nonsmall cell lung cancer cells. BMC Cancer 2010; 10: 269.

15 Yan H, Zhu Y, Liu B, Wu H, Li Y, Wu X, et al. Mitogen-activated protein kinase mediates the apoptosis of highly metastatic human non-small cell lung cancer cells induced by isothiocyanates. Br J Nutr 2011: 106; 1779-91.

16 Liu B, Wu X, Wang C, Liu Y, Zhou Q, Xu K. MiR-26a enhances metastasis potential of lung cancer cells via AKT pathway by targeting PTEN. Biochim Biophys Acta 2012; 1822: 1692-704.

$17 \mathrm{Xu} \mathrm{K}$, Thornalley PJ. Antitumour activity of sphingoid base adducts of phenethyl isothiocyanate. Bioorg Med Chem Lett 2000; 10: 53-4.

$18 \mathrm{Xu} \mathrm{K}$, Thornalley PJ. Signal transduction activated by the cancer chemopreventive isothiocyanates: cleavage of BID protein, tyrosine phosphorylation and activation of JNK. Br J Cancer 2001; 84: 670-3.

$19 \mathrm{Xu} \mathrm{K}$, Thornalley PJ. Involvement of glutathione metabolism in the cytotoxicity of the phenethyl isothiocyanate and its cysteine conjugate to human leukaemia cells in vitro. Biochem Pharmacol 2001; 61: 165-77.

20 Zhu Y, Liu A, Zhang X, Qi L, Zhang L, Xue J, et al. The effect of benzyl isothiocyanate and its computer-aided design derivants targeting alkylglycerone phosphate synthase on the inhibition of human glioma U87MG cell line. Tumour Biol 2015; 36: 3499-509.

21 Xiao D, Bommareddy A, Kim SH, Sehrawat A, Hahm ER, Singh SV. Benzyl isothiocyanate causes Fox01-mediated autophagic death in human breast cancer cells. PLoS One 2012; 7: e32597.

22 Naumann P, Fortunato F, Zentgraf H, Buchler MW, Herr I, Werner J. Autophagy and cell death signaling following dietary sulforaphane act independently of each other and require oxidative stress in pancreatic cancer. Int J Oncol 2011; 39: 101-9.

23 Ray A, Vasudevan S, Sengupta S. 6-Shogaol inhibits breast cancer cells and stem cell-like spheroids by modulation of Notch signaling pathway and induction of autophagic cell death. PLoS One 2015; 10 : e0137614.

24 Kumar D, Das B, Sen R, Kundu P, Manna A, Sarkar A, et al. Andrographolide analogue induces apoptosis and autophagy mediated cell death in $U 937$ cells by inhibition of PI3K/Akt/mTOR pathway. PLoS One 2015; 10: e0139657.

25 Gao L, Wang Y, Xu Z, Li X, Wu J, Liu S, et al. SZC017, a novel oleanolic acid derivative, induces apoptosis and autophagy in human breast cancer cells. Apoptosis 2015; 20: 1636-50.

26 Viola G, Bortolozzi R, Hamel E, Moro S, Brun P, Castagliuolo I, et al. MG-2477, a new tubulin inhibitor, induces autophagy through inhibition of the Akt/mTOR pathway and delayed apoptosis in A549 cells. Biochem Pharmacol 2012; 83: 16-26.

27 Ji Y, Di W, Yang Q, Lu Z, Cai W, Wu J. Inhibition of autophagy increases proliferation inhibition and apoptosis induced by the PI3K/mTOR inhibitor NVP-BEZ235 in breast cancer cells. Clin Lab 2015; 61: 1043-51.

28 Zhao L, Yang G, Shi Y, Su C, Chang J. Co-delivery of gefitinib and chloroquine by chitosan nanoparticles for overcoming the drug acquired resistance. J Nanobiotechnol 2015; 13: 57.

29 Hwang KE, Kim YS, Jung JW, Kwon SJ, Park DS, Cha BK, et al. Inhibition of autophagy potentiates pemetrexed and simvastatin-induced apoptotic cell death in malignant mesothelioma and non-small cell lung cancer cells. Oncotarget 2015; 6: 29482-96.

30 Sano R, Reed JC. ER stress-induced cell death mechanisms. Biochim Biophys Acta 2013; 1833: 3460-70.

31 Urra H, Dufey E, Lisbona F, Rojas-Rivera D, Hetz C. When ER stress reaches a dead end. Biochim Biophys Acta 2013; 1833: 3507-17.

32 Verfaillie T, Garg AD, Agostinis P. Targeting ER stress induced apoptosis and inflammation in cancer. Cancer Lett 2013; 332: 24964.

33 Kroemer G, Marino G, Levine B. Autophagy and the integrated stress response. Mol Cell 2010; 40: 280-93.

34 Jheng JR, Ho JY, Horng JT. ER stress, autophagy, and RNA viruses. Frontiers Microbiol 2014; 5: 388.

35 Shi JM, Bai LL, Zhang DM, Yiu A, Yin ZQ, Han WL, et al. Saxifragifolin $D$ induces the interplay between apoptosis and autophagy in breast cancer cells through ROS-dependent endoplasmic reticulum stress. Biochem Pharmacol 2013; 85: 913-26.

36 Hasanain M, Bhattacharjee A, Pandey P, Ashraf R, Singh N, Sharma $\mathrm{S}$, et al. alpha-Solanine induces ROS-mediated autophagy through activation of endoplasmic reticulum stress and inhibition of Akt/mTOR pathway. Cell Death Dis 2015; 6: e1860.

37 Li S, Guo L, Qian P, Zhao Y, Liu A, Ji F, et al. Lipopolysaccharide induces autophagic cell death through the PERK-dependent branch of the unfolded protein response in human alveolar epithelial A549 cells. Cell Physiol Biochem 2015; 36: 2403-17.

38 Hoyer-Hansen M, Bastholm L, Szyniarowski P, Campanella M, Szabadkai G, Farkas T, et al. Control of macroautophagy by calcium, calmodulin-dependent kinase kinase-beta, and Bcl-2. Mol cell 2007; 25: 193-205.

39 Hoyer-Hansen M, Jaattela M. Connecting endoplasmic reticulum stress to autophagy by unfolded protein response and calcium. Cell Death Differ 2007; 14: 1576-82. 